\title{
Cornstalk-derived Nitrogen-doped Partly-Graphitized Carbon as Efficient Metal-free Catalyst for Oxygen Reduction Reaction in Microbial Fuel Cells
}

Ye Sun ${ }^{\mathrm{a}, \mathrm{b}}$, Yaqiang Duan ${ }^{\mathrm{a}, \mathrm{b}}$, Liang Hao ${ }^{\mathrm{a}, \mathrm{b}}$, Zipeng Xing ${ }^{\mathrm{a}, \mathrm{b}}$, Ying Dai ${ }^{\mathrm{a}, \mathrm{c} *}$, Rui $\mathrm{Li}^{\mathrm{a}, \mathrm{b}}$, Jinlong Zou ${ }^{\mathrm{a}, \mathrm{b}, *}$

${ }^{a}$ Key Laboratory of Functional Inorganic Material Chemistry, Ministry of Education of the People's

Republic of China, School of Chemistry and Materials Science, Heilongjiang University, Harbin 150080, China.

${ }^{b}$ Key Laboratory of Chemical Engineering Process and Technology for High-Efficiency Conversion, College of Heilongjiang Province, School of Chemistry and Materials Science, Heilongjiang University, Harbin 150080, China.

${ }^{\mathrm{c} S c h o o l ~ o f ~ C i v i l ~ E n g i n e e r i n g, ~ H e i l o n g j i a n g ~ I n s t i t u t e ~ o f ~ T e c h n o l o g y, ~ H a r b i n ~ 150050, ~ C h i n a . ~}$

\section{Corresponding author (s):}

* Ying Dai, Jinlong Zou

${ }^{\mathrm{a} X u e f u}$ Road 74 ${ }^{\#}$, Nangang District, Harbin, 150080, China.

Tel.: +86-451-86608549; Fax: +86-451-86608549

E-mail: zjh_0308@126.com (Y. Dai); zoujinlong@aliyun.com (J. L. Zou) 
Table S1 Results of element content analysis by XPS of NPGCs.

\begin{tabular}{ccccc}
\hline Samples & Fe (at. \%) & O (at. \%) & N (at. \%) & C (at. \%) \\
\hline NPGC-700 & 0.00 & 10.34 & 8.43 & 81.23 \\
NPGC-800 & 0.00 & 9.33 & 6.07 & 84.60 \\
NPGC-900 & 0.00 & 9.96 & 3.84 & 86.20 \\
NPGC-1000 & 0.00 & 7.30 & 3.15 & 89.55 \\
NPGC-1050 & 0.00 & 6.47 & 1.78 & 91.75 \\
\hline
\end{tabular}


Table $\mathbf{S} 2 \mathrm{~V}_{\mathrm{OC}}$ and $\mathrm{P}_{\max }$ for MFCs with different cathodes.

\begin{tabular}{|c|c|c|c|c|c|}
\hline \multirow{2}{*}{ Samples } & \multicolumn{2}{|c|}{ Initial cycles } & \multicolumn{2}{|c|}{ Final cycles } & \multirow{2}{*}{ Decline $(\%)$} \\
\hline & $\mathrm{V}_{\mathrm{OC}}(\mathrm{V})$ & $\mathrm{P}_{\max }\left(\mathrm{mW} \mathrm{m} \mathrm{m}^{-2}\right)$ & $\mathrm{V}_{\mathrm{OC}}(\mathrm{V})$ & $\mathrm{P}_{\max }\left(\mathrm{mW} \mathrm{m} \mathrm{m}^{-2}\right)$ & \\
\hline NPGC-700 & $0.76 \pm 0.01$ & $502 \pm 13$ & $0.78 \pm 0.01$ & $409 \pm 15$ & 18.5 \\
\hline NPGC-800 & $0.80 \pm 0.01$ & $830 \pm 17$ & $0.76 \pm 0.01$ & $705 \pm 31$ & 15.1 \\
\hline NPGC-900 & $0.78 \pm 0.01$ & $996 \pm 21$ & $0.79 \pm 0.01$ & $898 \pm 21$ & 9.8 \\
\hline NPGC-1000 & $0.80 \pm 0.01$ & $1122 \pm 32$ & $0.79 \pm 0.01$ & $1008 \pm 27$ & 10.2 \\
\hline NPGC-1050 & $0.78 \pm 0.01$ & $1082 \pm 27$ & $0.75 \pm 0.01$ & $810 \pm 19$ & 25.1 \\
\hline $\mathrm{Pt} / \mathrm{C}$ & $0.73 \pm 0.01$ & $988 \pm 11$ & $0.73 \pm 0.01$ & $615 \pm 38$ & 37.8 \\
\hline
\end{tabular}


Table S3 The electrochemical impedance fitting results of different cathodes.

\begin{tabular}{ccc}
\hline Cathodes & $\mathrm{R}_{\mathrm{s}}(\Omega)$ & $\mathrm{R}_{\mathrm{ct}}(\Omega)$ \\
\hline NPGC-700 & $84.7 \pm 0.4$ & $47.4 \pm 0.3$ \\
NPGC-800 & $77.3 \pm 0.3$ & $45.3 \pm 0.5$ \\
NPGC-900 & $39.2 \pm 0.2$ & $38.3 \pm 0.2$ \\
NPGC-1000 & $34.4 \pm 0.3$ & $27.6 \pm 0.2$ \\
NPGC-1050 & $44.8 \pm 0.4$ & $34.4 \pm 0.3$ \\
Pt/C & $35.9 \pm 0.2$ & $23.8 \pm 0.3$ \\
\hline
\end{tabular}




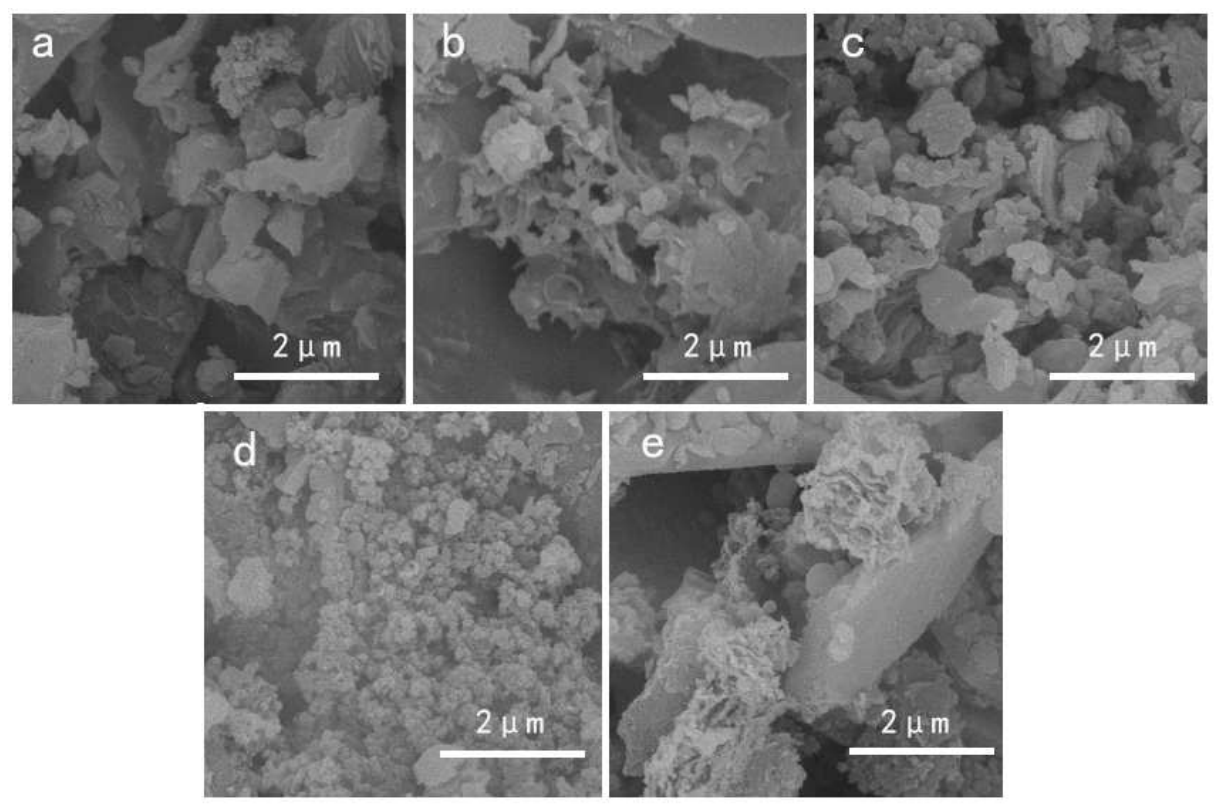

Figure S1. SEM of NPGC-x (x=700 (a), 800 (b), 900 (c), 1000 (d), and 1050 (e)). 

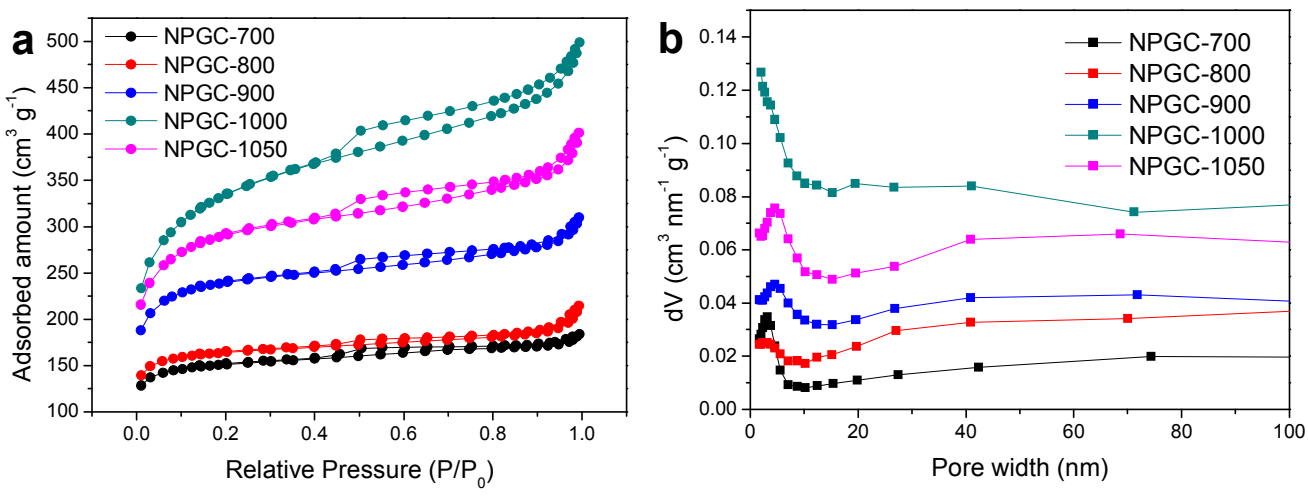

Figure S2. (a) $\mathrm{N}_{2}$ adsorption-desorption isotherms, (b) pore-size distributions of NPGCs. 

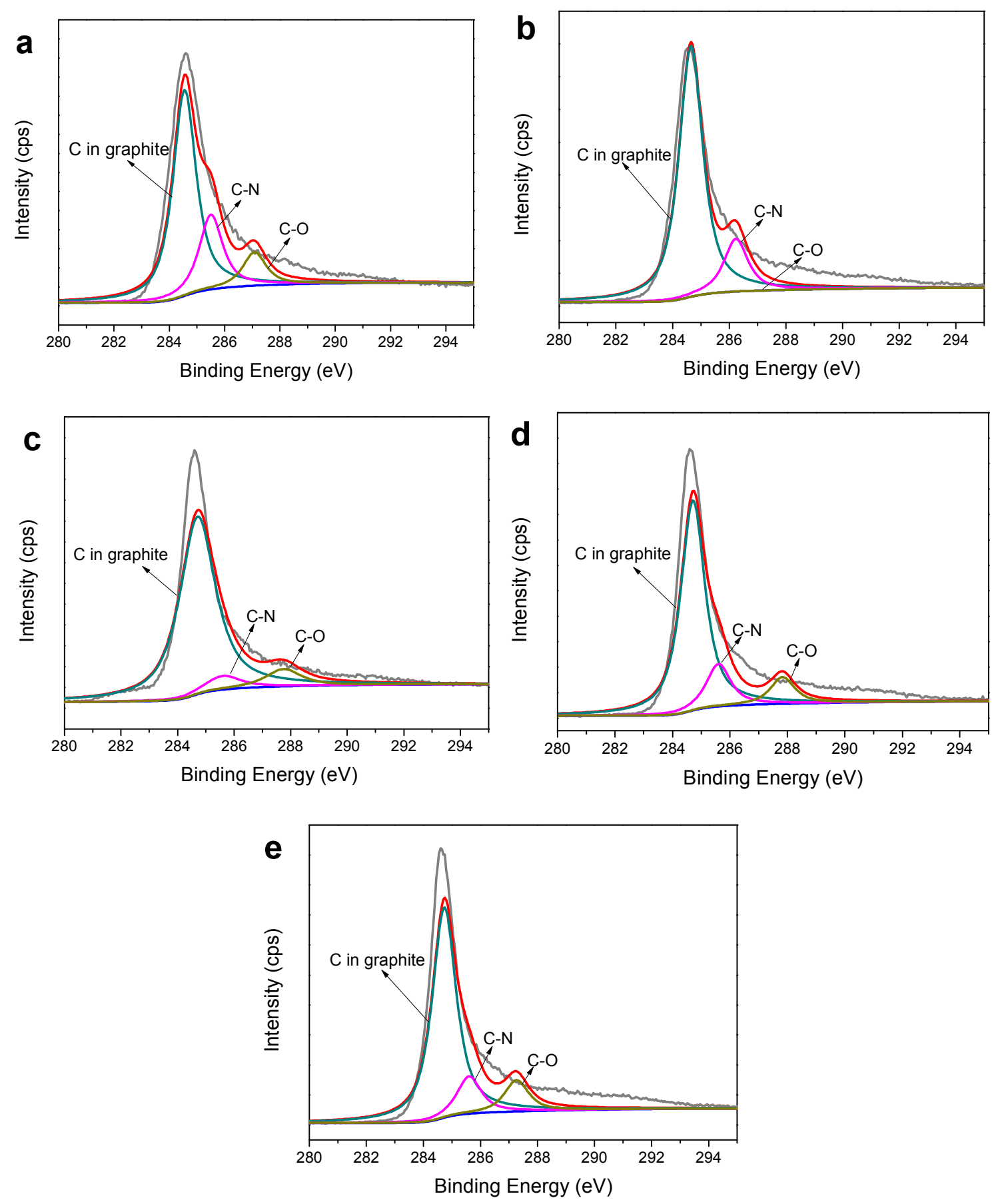

Figure S3. High resolution XPS of C 1s spectra for NPGC-x (x=700(a), 800(b), 900(c), 1000(d),

and 1050(e)). 

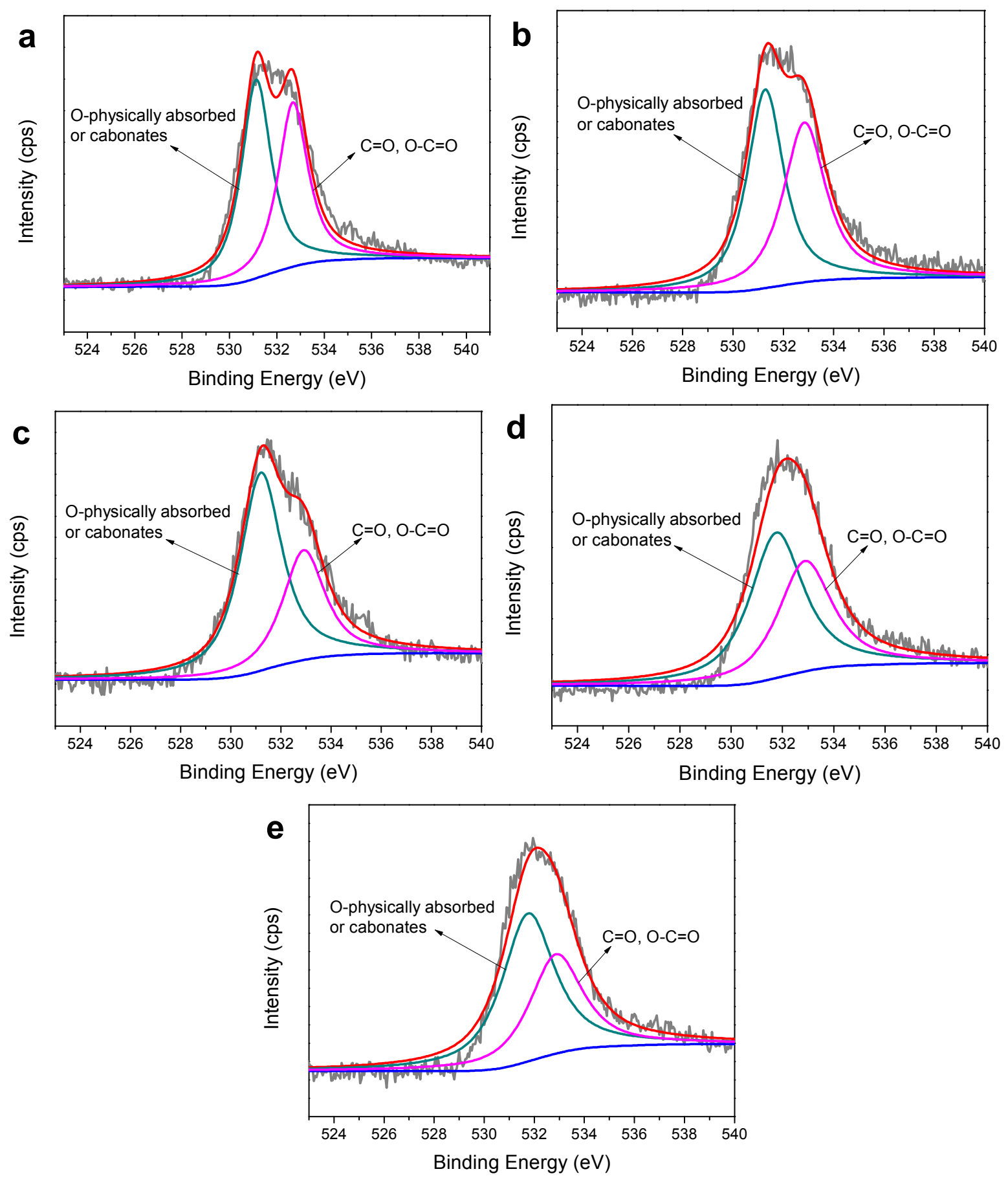

Figure S4. High resolution XPS of O 1s spectra for NPGC-x (x=700(a), 800(b), 900(c), 1000(d), and 1050(e)). 


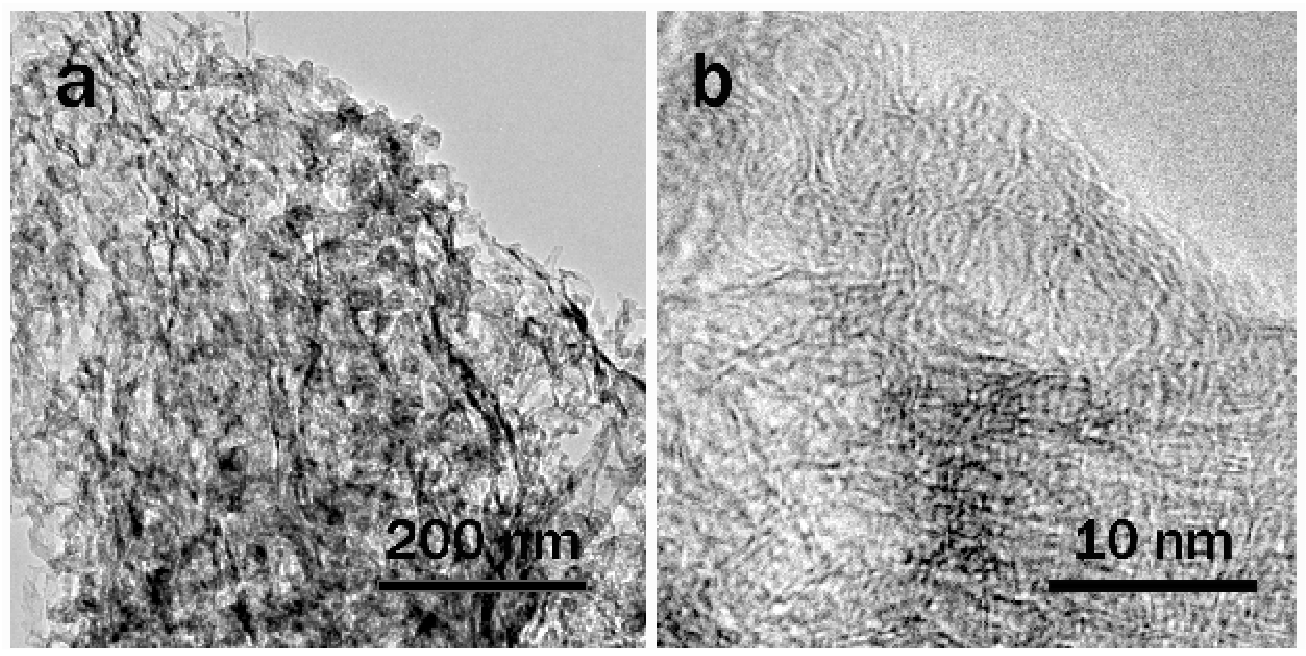

Figure S5. TEM images of NPGC-900 ( $a$ and $b$ ). 


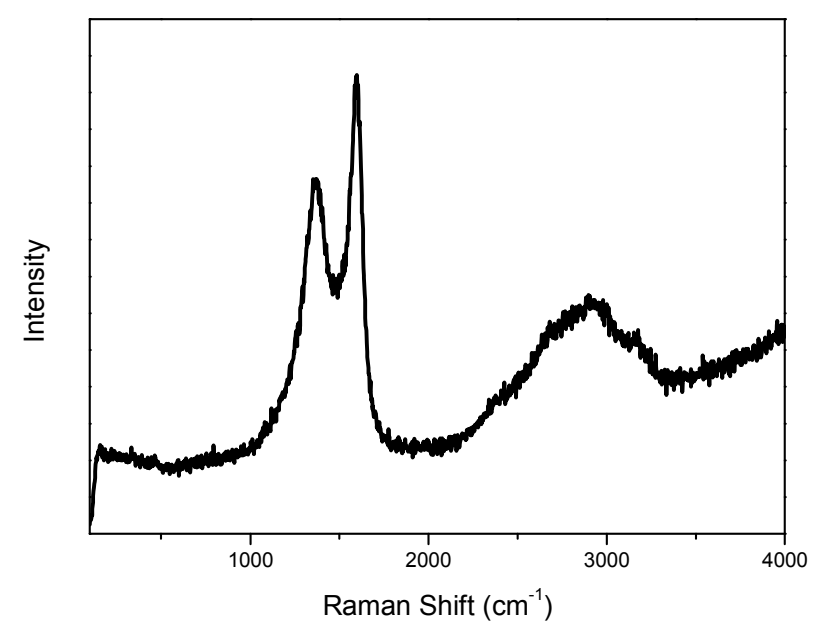

Figure S6. Raman spectrum of NPGC-1000.

Raman spectroscopy can identify the surface crystal structure of carbon materials. As shown in Figure S6, two main peaks located at around 1380 and $1604 \mathrm{~cm}^{-1}$ are observed in the Raman spectrum, corresponding to the D and G bands of NPGC-1000, respectively. The D band represents the degree of carbon atoms in defect, while the $G$ band results from the vibration mode for $\mathrm{sp}_{2}$-hybridized graphitic carbon. Another peak at around $2890 \mathrm{~cm}^{-1}$ can be assigned to a combination of $2 \mathrm{D}$ and $\mathrm{D}+\mathrm{G}$ bands, which indicates a high degree of disorder in the NPGC structure. $^{17,19}$ This may be attributed to the nitrogen doping, which leads to the formation of more defects in C skeleton. 